\title{
Diagnosis and Treatment of Affections of the Urethra in Male Ruminants: A Review of 403 Cases
}

\author{
Nabil Ahmed Misk ${ }^{1}$, Tarik Nabil Misk ${ }^{2}$ and Mohamed Abdelrahman Semieka ${ }^{1}$ \\ ${ }^{1}$ Department of Surgery, Anesthesiology \& Radiology, Faculty of Veterinary Medicine, Assiut \\ University, Assiut, Egypt \\ ${ }^{2}$ Department of Surgery, Anesthesiology \& Radiology, Faculty of Veterinary Medicine, Menofia \\ University, Sadat Branch, Sadat, Egypt
}

Correspondence should be addressed to: Nabil Ahmed Misk; nabil.misk@gmail.com

Received 19 April 2013; Accepted 8 May 2013; Published 29 July 2013

Academic Editor: Omid Azari

Copyright (C) 2013 Nabil Ahmed Misk, Tarik Nabil Misk and Mohamed Abdelrahman Semieka. Distributed under Creative Commons CC-BY 3.0

\begin{abstract}
The aim of the present study was to review different surgical affections of the penile urethra in male ruminants [cattle, buffaloes, sheep and goats] with special reference to diagnosis and outcome of surgical treatment.

The study was carried out on a total number of 403 animals suffering from different affections of the penile urethra. Diagnosis was performed depending on case history, clinical signs, radiographic examination and sometimes exploratory puncture. Different affections were recorded namely; dilatation [45], hypospadia [17], obstruction [320] and rupture [21]. Surgical treatment was conducted and the results were encouraging.
\end{abstract}

Keywords: Penile urethra - Ruminants.

\section{Introduction}

The urethra in male ruminants is a long tube extends from the bladder to the glans penis. It passes caudad on the floor of the pelvis, turns around the ischialarch, forming a sharp bend and passes craniad as a part of the penis, enclosed in the corpus cavernosum urethrae. Just caudal to the scrotum the penis and penile urethra form a s-shaped curve, the sigmoid flexure. In rams, the penile urethra lies in a groove on the ventral surface of the corpus cavernosum. Its terminal part projects commonly about $3-4 \mathrm{~cm}$ beyond the glans penis forming a twisted processus urethrae (Budras et al., 2011, Ashdown and Done, 2010, Clayton and Flood, 1996).

Many affections of the penile urethra were mentioned in the available literature including congenital anomalies such as hypospadias in cattle, sheep, and goat(Azari et al., 2010, Sakhaee and Azari, 2009, Ladds, 1993, Smith, 2009, Blowey and Weaver, 2011), urethral dilatation in 
calves and goats (Gasthuys et al., 1996, Sndak et al., 2010, Kamiloglu et al., 2003, Ozturk et al., 2002, Geccelep and Alkan, 2000, Karras et al., 1992) and acquired affections such as urethral obstruction and rupture in buffaloes, cattle and sheep (Blowey and Weaver, 2011, Dabas, 2009, Misk and Semieka, 2003, Zabady, 1996, Van Metra et al., 1996, Tyagi and Singh, 1996, Gasthuys et al., 1993, Ismail et al., 2007).

The aim of the present study was to report different affections of the penile urethra in ruminants with special reference to diagnosis and outcome of surgical treatment.

\section{Materials and Methods}

The present study was carried out on a total number of 403 male ruminants suffering from different affections of the penile urethra [table 1]. The majority of cases were examined during the periodical visits to the village ofveterinary clinics and some cases were recorded at the Veterinary Teaching Hospital of the Faculty of Veterinary Medicine, Assiut University between the periods from 1999 - 2012.

All operations were performed under effect of local infiltration analgesia using Lidocaine HCL 2\%. Tranquilization withXylazine HCL $2 \%$ in a dose rate of $0.05 / \mathrm{kg}$ was used in cattle and buffaloes.

Initialdiagnosis depends mainly on case history and clinical presentation of animals.
Lateral and vetrodorsalradiographyof the caudal abdomen and pelvic region and exploratory puncture were performed for conformation of diagnosis. Proper surgical treatment was carried out.

In urethral dilatation, aurethrostomy was performed at the most caudal part of the swelling. The dilated part of the urethra in front of the induced fistula was resected. In urethral dilatation in bulls, urethrostomy was created at the most upper part of the dilated urethra. The dilated part of the urethra below the induced fistula was resected or obliterated. In hypospadias, the bared mucous membrane of the urethra was covered by suturing the skin edges after their dissection from the underlying tissues. The displaced urethral orifice was widened(Misk, 2008).

Perineal urethrostomy was carried out in cases of urethral obstruction only and the same operation in addition to laparocystorrhaphy were performed in cases of urethral obstruction accompanied by bladder rupture (Misk and Semieka, 2003). In cases of urethral rupture, perineal urethrostomy was performed at the perineal region. In addition, several skin incisions were applied to the infiltrated areas with urine. Urethral obstruction in rams and bucks were treated by amputation of the urethral process.

Table 1: Illustrates Different Affections of the Penile Urethra in Male Ruminants and the Number of Affected Animals

\begin{tabular}{|c|c|c|c|c|c|}
\hline Type of Affections & $\begin{array}{c}\text { Bulls } \\
\text { (Holstein- } \\
\text { Friesians } \\
\text { \&Local } \\
\text { breeds) }\end{array}$ & $\begin{array}{c}\text { Buffalobulls } \\
\text { (Bubalusbubalis) }\end{array}$ & $\begin{array}{c}\text { Rams } \\
\text { (Rahmany\&Barki } \\
\text { local breeds) }\end{array}$ & $\begin{array}{c}\text { Bucks } \\
\text { (Baladi\&Zarabi } \\
\text { local breeds) }\end{array}$ & Total \\
\hline $\begin{array}{c}\text { Urethral } \\
\text { dilatation }\end{array}$ & 8 & 3 & 4 & 30 & 45 \\
\hline Hypospadias & 3 & 3 & 2 & 9 & 17 \\
\hline $\begin{array}{c}\text { Urethral } \\
\text { obstruction }\end{array}$ & 217 & 86 & 7 & 10 & 320 \\
\hline Urethral rupture & 14 & 7 & - & - & 21 \\
\hline Total & 242 & 99 & 13 & 49 & 403 \\
\hline
\end{tabular}




\section{Results}

Urethral dilatation is a congenital condition recorded in 45 male ruminants [small ruminant $=34$, large ruminant $=11]$ [Table 1]. In small ruminants, the dilatation occured at the ventral aspect of the urethra cranial to the scrotal sac [15 kids] or along its whole length [19 kids]. In newly born animals failure to urinate and accumulation of the urine in the dilated part of the urethra were evident [Figure 1,2].

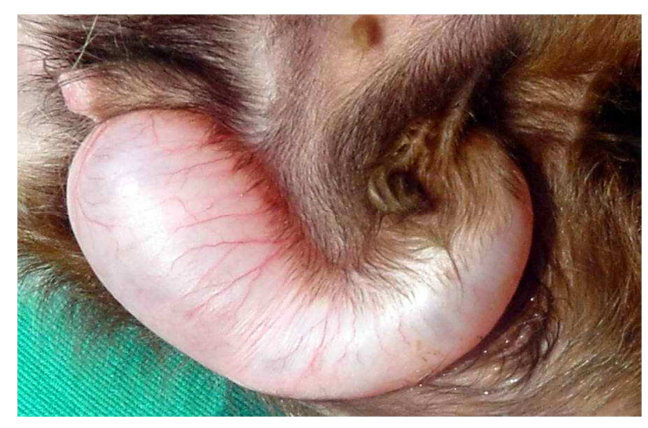

Figure 1: Urethral Dilatation in a Kid

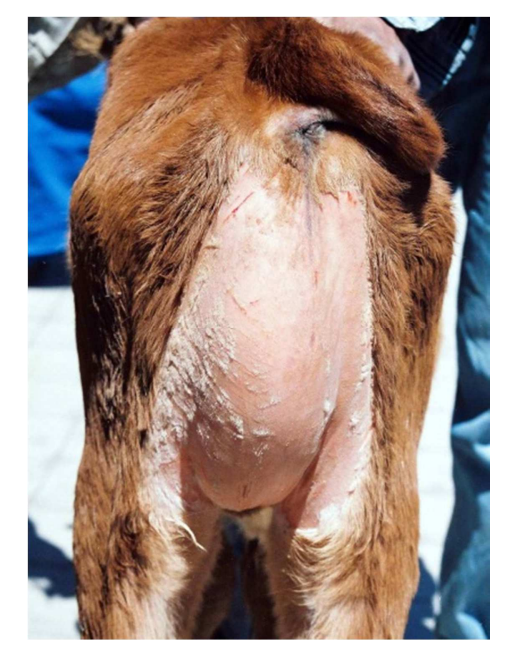

Figure 2: Penile Urethral Dilatation in a Calf

In large ruminants, urethral dilatation in bulls was recorded in 11 bulls [Table 1]. The condition was recorded in newly born animals up to 18 months of age. Dilatation was seen along the whole length of the penile urethra at the perineal region starting just below the ischial arch and extended to the base of the scrotum. Dysuria and dripping of urine were the most common signsin those cases. Contrast radiography using intra-urethral injection of Urografin $76 \%$ was diagnostic. [Figure 3]. 


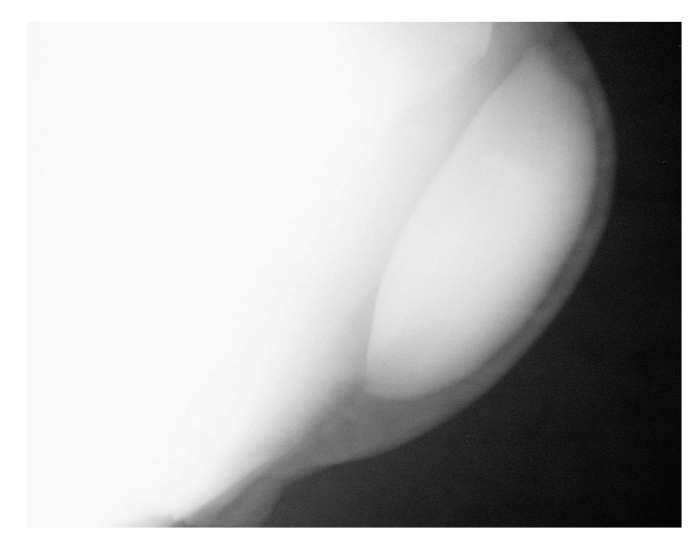

Figure 3: Contrast Radiography of the Dilated Urethra in a Calf

Treatment was conducted in small ruminants by establishment of
urethrostomy at the most caudal part of the dilatation with urethrectomy of the dilatation. Recovery occured in 31 cases out of 34. Wound dehiscence occurred in three cases and re-establishment of the urethral fistulae was performed.

In bulls urethrostomy was conducted at the proximal part of the dilatation distal to the ischial arch. The dilated part distal to the induced fistula was excised in 4 cases and obliterated in 7 cases. Recovery was uneventful except in one case in which wound dehiscence was resulted and was corrected in routine manner.

\begin{abstract}
Hypospadia is a congenital defect characterized by presence of a urethral fissure at the ventral aspect of penile urethra. Urethral fissure was seen along the whole length of the penile urethral [13 cases] [Figure 4] or along the penile urethra cranial to the scrotum [4 cases] [Figure 5]. The urethral orifice was displaced caudad to the level of the scrotum or to the level of the anal opening. The bared mucous membrane of the penile urethra was subjected to a variable degree of trauma.
\end{abstract}

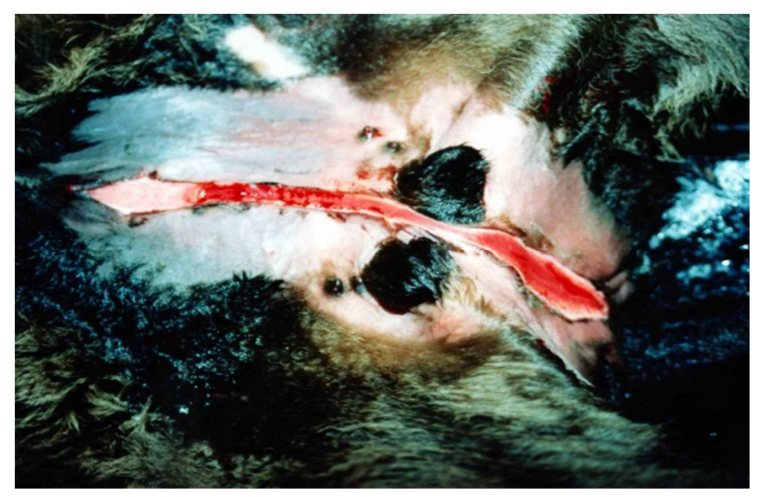

Figure 4: Hypospadia in a Kid 


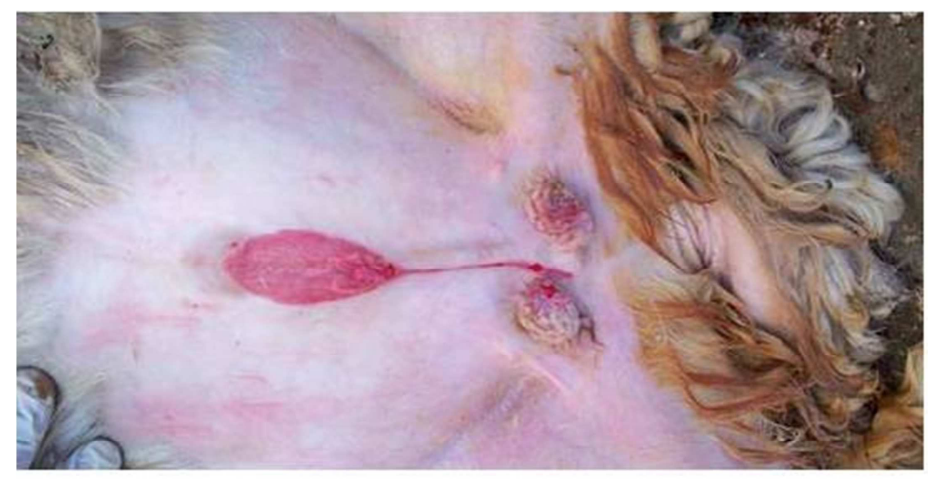

Figure 5: Hypospadia in a Ram Affecting the Urethra in Front of the Scrotum

Treatment was conducted under effect of local analgesia using local infiltration of $2 \%$ Lidocaine HCL along the edges of urethral fissure. Dissection of the skin edges at both sides of the ventral fissure was performed and then continuous silk sutures were applied along its whole length just to cover the mucous membrane and closed the lumen. The displaced urethral orifice was widened in some cases [5 out of 17] to keep flow of urine intact.

Urethral obstruction was recorded in 320 animals [Table 1]. The location of obstruction with urolith was detected at the distal part of the sigmoid flexure in all cases of bulls and buffalo bulls and at the urethral process in rams and bucks. The age of affected bulls varied between 2-24 months. They were presented at 1-6 days of anuria. Cases of urethral obstruction in rams and bucks were 4-12 months old and presented to the clinic at 1-5 days of anuria.
Cattle and buffalo bulls with urethral obstruction (303 animals) were divided into two groups of animals:

Group 1: Bulls have urethral obstruction only [111 animals].

Group 2: Bulls have urethral obstruction and rupture of urinary bladder [192 animals].

Animals with urethral obstruction only displayed signs of short period of moderate colic including teeth grinding, rear leg stampling and kicks at the abdomen. They assumed repeatedly the posture for urination and the tail may be seen moving up and down with no urination or few droplets resulted from these attempts. On rectal palpation, the bladder was found distended and the pelvic urethra was found pulsating. Urethral calculus could be seen radiographically [Figure 6].

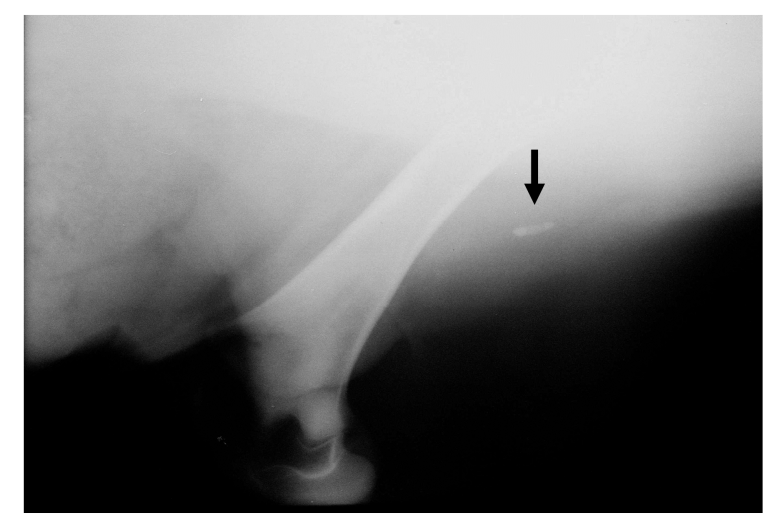

Figure 6: Lateral Radiography of the Perineal Region Showing Urethral Calculus at the Distal Part of Sigmoid Flexure (Black Arrow) in a Calf 
Animals with urethral obstruction and ruptured urinary bladder showed signs of abdominal distention without any evidence of colic [Figure 7]. The bladder felt empty on rectal palpation. Abdominal paracentesis revealed copious amount of clear yellowish fluid, which by its odour was mostly identified as urine.

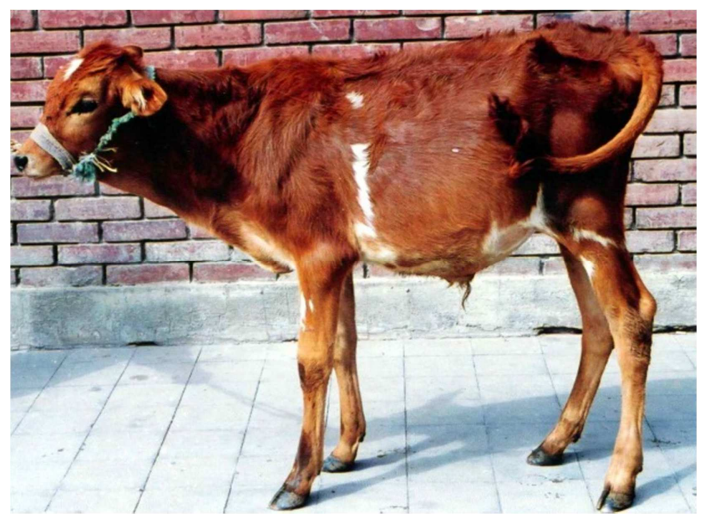

Figure 7: A Calf with Abdominal Distension Due to Rupture of Urinary Bladder

Perineal urethrostomy was performed in cases of urethral obstruction only [Figure 8]. Ninety threeanimals recovered, 7 died during operation and in 11 cases the fate of the animal could not be recorded.

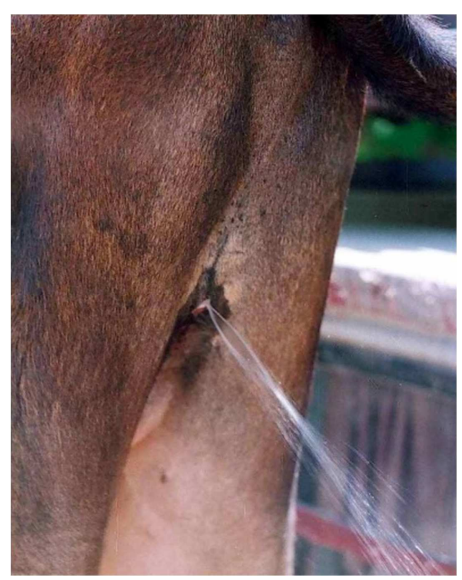

Figure 8: Perineal Urethrostomyone Month after Operation in a Calf

Perineal urethrostomy and cystorrhaphy were performed for treatment of cases of urethral obstruction with rupture of urinary bladder. Recovered cases were 149 while 21 died during surgery and in 22 animals the fate could not be recorded.

Urethral rupture occurred in 15 bulls and 6 buffalo bulls. Animals presented at the day 6-15 of anuria. The site of rupture happened at the site of obstruction at the distal part of the sigmoid flexure. The subcutaneous tissues at the ventral abdominal wall, preputeal, scrotal and perineal regions become infiltrated with urine resulting in frog-belly shaped abdominal contour. A transverse line at the lateral abdominal wall was evident in all animals representing the line of separation between non-infiltrated and infiltrated tissues with urine. Violet discoloration of the skin at the infiltrated areas appeared first then necrosis and sloughing of some areas of skin occurred later on [Figure 9a, b; 10]. 


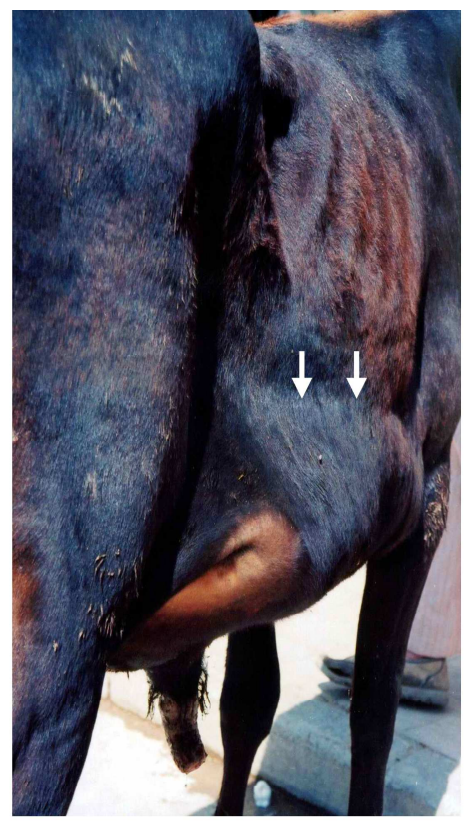

Figure 9a: Frog Belly Abdomen Due to Rupture of the Urethra in a Calf. Note: The Line of Separation between Non-Infiltrated and Infiltrated Tissues with Urine

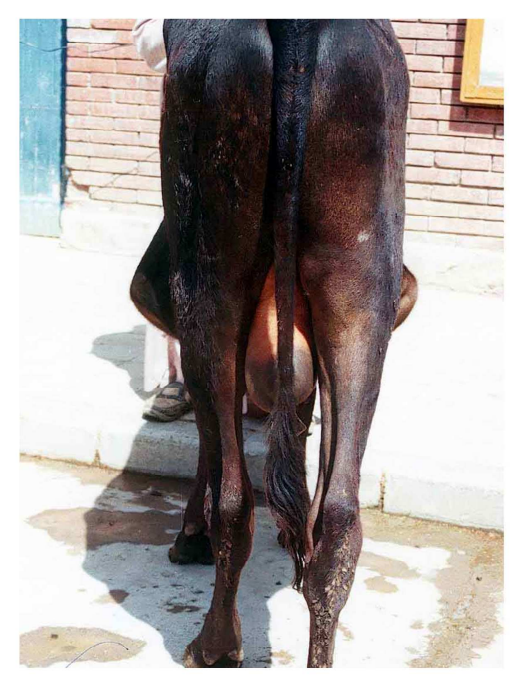

Figure 9b: Frog Belly Abdominal Contour 


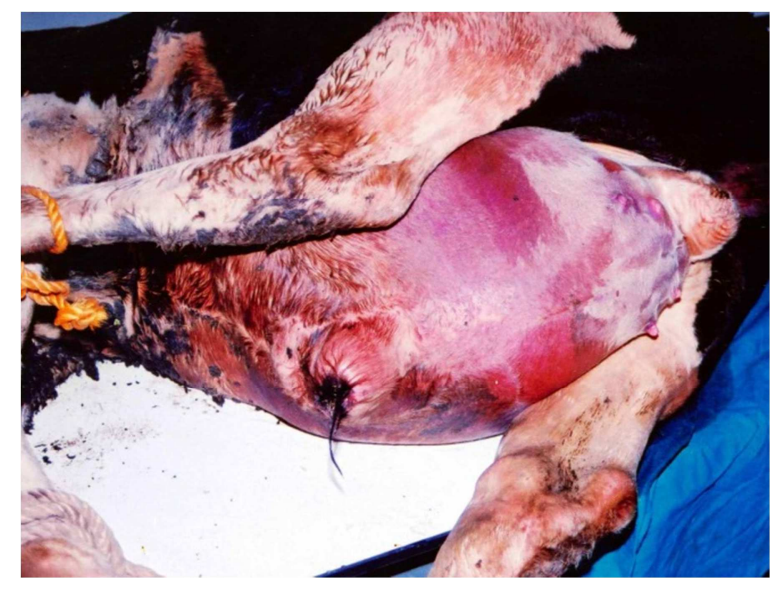

Figure 10: Infiltration of the Scrotal, Ventral Abdominal and Preputeal Regions with Urine in a Case of Ruptured Urethra in a Calf

Perineal urethrostomywere performed at the healthy area of the perineal region mostly close to the ischial arch. Several skin incisions were performed over the infiltrated areas [Figure 11]. Zinc oxide ointment was applied over the healthy areas surrounding the affected areas and cod-liver oil was applied over the sloughed and necrotic tissues.

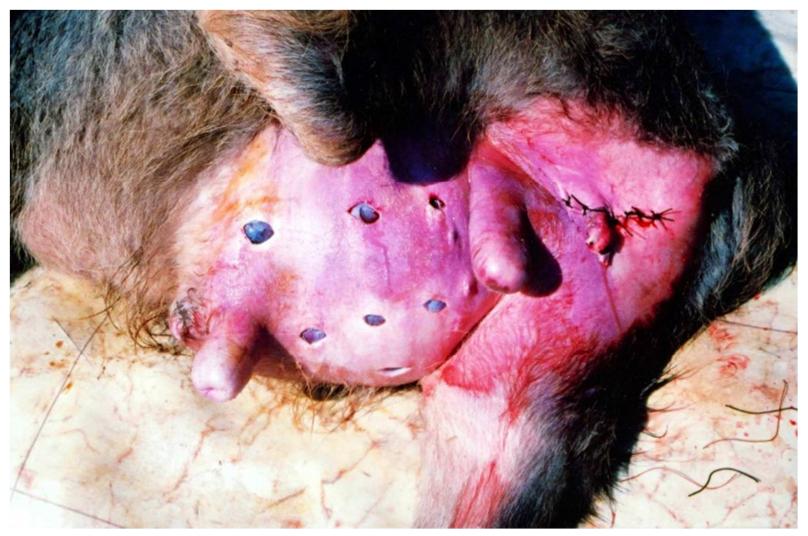

Figure 11: A Calf after Perineal Urethrostomy and Multiple Skin Incisions in a Case of Urethral Rupture

Recovery was detected in 15 cases and in 6 cases the fate of treatment couldnot be recorded.

\section{Discussion}

Congenital urethral dilatation in goats was mentioned in the available literature (Sndak et al., 2010, Kamiloglu et al., 2003, Karras et al., 1992). Examination of the affected animals revealed that the skin and urethral wall were intact and dilated together at the ventral aspect of the penis starting at the ischial arch or at the level of the scrotum craniad to a variable distances from the preputeal orifice. Treatment was restricted to a creation of urethral fistula at the caudal part of the swelling (Kamiloglu et al., 2003). Recovery was uneventful and usually resulted in free discharge of urine from the urethral fistula (Sndak et al., 2010, Kamiloglu et al., 2003, Karras et al., 1992).

Urethral dilatation in male calves or buffalo - calves was prescrotal and seen early in life [3-12 months] and appears to have a congenital back ground (Ozturk et al., 2002, Geccelep and Alkan, 2000). The dilatation 
started just below the ischial arch and extended to the level of the scrotal sacs. The sigmoid flexure of the penis appears to be not included in this process. The flow of urine was not interrupted as in cases of urethral dilatation in kids however the presence of a large swelling at the perineal region is cosmetically non acceptable in addition to the continuous contamination of the perineal region with voided fecal matters. Creation of a urethral fistula, suggested by the authors of this study, appears to be the only acceptable way for treatment of such cases at the moment. Resection or obliteration of the dilated part was performed, however the later was more practical but time consuming (Gasthuys et al., 1996).

Hypospadias, urethral fissure at the ventral aspect of penile urethra, was mentioned in the available literatures (Sakhaee and Azari, 2009, Azari et al., 2010, Sndak et al., 2010). The urethral fissure affects the penile urethra cranial and caudal to the scrotal sac. Some authors classify hypospadia into 4 types; palanetic, penile, scrotal and perineal (Ladds, 1993). A conservative treatment was suggested to protect the mucous membrane of the urethral fissure from trauma by dissection and retraction of the skin edges for obliteration of the ventral defect keeping in consideration the presence of an intact urethral opening.

The predilection site of urethral obstruction and/or rupture is mainly at the level of the distal part of the sigmoid flexure of the penis behind the site of insertion of the retractor penis muscle. The urethra at this level cannot dilate dorsally and laterally due to presence of the corpus cavernosum penis and cannot dilate ventrally due to the presence of the insertion of retractor penis muscle (Misk and Semieka, 2003). Complete obstruction at this level mostly leads to bladder distention and later on to bladder rupture. In rare cases, rupture of the urethra occurs at the level of obstruction before bladder rupture as a result of pressure necrosis supervenes from rough surface of the stones.

\section{References}

Ashdown, R. R. \& Done, S. (2010). 'Colour Atlas of Veterinary Anatomy - Volume 1: The Ruminants,' London, Elsevier Ltd.

Azari, O., Sakhaee, E. \& Emadi, L. (2010). "Permanent Urethrostomy for Treatment of Caprine Hypospadias," American Journal of Animal and Veterinary Sciences, 5, 100103.

Blowey, R. W. \& Weaver, A. D. (2011). Color Atlas of Diseases and Disorders of Cattle, Elsevier Ltd.

Budras, K.- D., Habel, R. E., Mülling, C. K. W. \& Greenough, P. R. (2011). 'Bovine Anatomy Hannover,' Germany., Schlüterscheverlagsgesellschaftmbh \& Co. $\mathrm{Kg}$.

Clayton, H. M., Flood, P. F., Mandeville, D. \& Farrow, C. (1996). Color Atlas of Large Animal Applied Anatomy, Mosby - Wolfe.

Dabas, V. S. (2009). "Urethral Rupture and Permanent Perineal Urethrostomy in a Male Kankrej Calf," Intas Polivet, 10258 259.

Gasthuys, F., Martens, A. \& De Moor, A. (1996). "Surgical Treatment of Urethral Dilatation in Seven Male Cattle," Veterinary Record, 138, 17-9.

Gasthuys, F., Steenhaut, M., De Moor, A. \& Sercu, K. (1993). "Surgical Treatment of Urethral Obstruction due to Urolithiasis in Male Cattle: A Review of 85 Cases," Veterinary Record, 133, 522-6.

Geccelep, M. \& Alkan, I. (2000). 'Congenital Urethral Dilatation in a Male Montaphon Calf,' Israel Journal of Veterinary Medicine, $55,10-12$.

Ismail, Z. B., Al-Rukibat, R. \& Al-Zghoul, M. B. (2007). "Renal and Epididymal Infarctions Associated with Chronic Obstructive Urolithiasis in a Suffolk Ram," American Journal of Animal and Veterinary Sciences, 2, 29-31. 
Kamiloglu, A., Atalan, G., Ozturk, S. \& Beytut, E. (2003). "Urethral Dilatation and Its Surgical Treatment in a Lamb," Indian Veterinary Journal, 80, 1171-1172.

Karras, S., Modransky, P. \& Welker, B. (1992). "Surgical Correction or Urethral Dilatation in an Intersex Goat," Journal of the American Veterinary Medical Association, 201, 1584-1586.

Ladds, P. W. (1993). "Congenital Abnormalities of the Genitalia of Cattle Sheep, Goats, and Pigs," The Veterinary Clinics of North America: Food Animal Practice, 9, 127-144.

Misk, N. A. (2008). 'Atlas of Veterinary Surgery,' Assiut, Assiut City Press.

Misk, N. A. \& Semieka, M. A. (2003). "Clinical Studies on Obstructive Urolithiasis in Male Cattle and Buffaloes," Assiut Veterinary Medical Journal, 49, 258-274.

Ozturk, S., Klc, E., Aranc, A. \& Uygunturk, A. (2002). 'A Case of Aplasia Penis, Anorchidism and Urethral Dilatation in a Montaphon Calves,' Kafkas universitesi veteriner fakultesi dergisi, 8, 63-65.

Sakhaee, E. \& Azari, O. (2009). "Hypospadias in Goats," Iranian Journal of Veterinary Research, 10, 298-301.

Smith, B. P. (2009). Large Animal Internal Medicine, Mosby- Elsevier Inc.

Sndak, N., Sahn, T. \& Brck, H. S. (2010). "Urethral Dilatation, Ectopic Testis, Hypoplasia Penis, and Phimosis in a Kilis Goat Kid," Kafkas universitesi veteriner fakultesi dergisi, 16, 147-150.

Tyagi, R. P. S. \& Singh, J. (1996). 'Ruminant Surgery: A Textbook of Surgical Diseases of Cattle, Buffaloes, Camels, Sheep and Goat,' Cbs Publishers and Distributors.

Van Metra, D. C., House, J. K., Smith, B. P., George, L. W., Angelos, S. M. \& Angelos, J. A. (1996). "Obstructive Urolithiasis in Ruminants: Medical Treatment and Urethral Surgery," The Compendium, 317327.
Zabady, M. K. (1996). 'Studies on Urolithiasis in Ruminants.Department of Surgery,' Anesthesiology \& Radiology.Cairo, Cairo University. 